\title{
ATUAÇÃO DO PROFISSIONAL DO CONSULTÓRIO NA RUA FRENTE À MULHER EM SITUAÇÃO DE RUA NA CIDADE DE FEIRA DE SANTANA-BA
}

\author{
Amanda Pinheiro Magalhães ${ }^{1}$, Maria Yaná Guimarães Silva Freitas ${ }^{2}$ \\ 1. Voluntária PEVIC, Graduanda em Enfermagem, Universidade Estadual de Feira de Santana, e-mail: \\ apmagalhaes94@gmail.com. \\ 2. Orientadora, Departamento de Saúde, Universidade Estadual de Feira de Santana, e-mail: \\ yana.guimaraess@mail.com.
}

PALAVRAS-CHAVE: Mulheres em situação de rua; Atuação profissional; Consultório na rua.

\section{INTRODUÇÃO}

A atuação do profissional de saúde frente às questões da mulher constitui um desafio no que diz respeito às diversas formas de cuidado, necessitando de um olhar ampliado e escuta sensível para atender as demandas dessa categoria, valorizando assim, as relações de gênero, raça/cor, classe e geração no processo de saúde e adoecimento, além de garantir práticas de atenção que assegurem o acesso as ações resolutivas para as mulheres (COELHO, 2009).

$\mathrm{Na}$ tentativa de oferecer uma atenção especializada e atender às necessidades de saúde da população em situação de rua, houve a criação das Equipes de Consultório na Rua (eCR), através da Portaria $\mathrm{n}^{\mathrm{o}} 122$, de 25 de janeiro de 2012, atribuindo a mesma a busca ativa e o cuidado a essa população (BRASIL, 2012a).

Nesse sentido, foi elaborada a seguinte questão de pesquisa: Como acontece a atuação do profissional da equipe do Consultório na Rua frente à saúde das mulheres em situação de rua? Assim, o estudo tem como objetivo descrever a atuação do profissional da equipe do Consultório na rua frente à saúde da mulher em situação de rua na cidade de Feira de Santana-BA.

\section{METODOLOGIA}

Trata-se de uma pesquisa de caráter exploratório e descritivo com abordagem qualitativa. $\mathrm{O}$ estudo foi realizado na base operacional da equipe do Consultório na Rua (eCR) na cidade de Feira de Santana - Bahia e nos espaços urbanos onde as mulheres em situação de rua eram encontradas. Os participantes deste estudo foram cinco 
profissionais de saúde que atuavam na eCR. A coleta de dados foi feita a partir da entrevista semiestruturada e a observação não participante ou passiva. Os instrumentos de coleta de dados foram o roteiro de entrevista semiestruturada e de observação não participante, detalhado no diário de campo. Os dados foram analisados com a técnica de análise de conteúdo temática de Bardin. Este estudo respeitou os aspectos éticos da Resolução n $^{\circ}$ 466, de 12 de dezembro de 2012 (BRASIL, 2012b) e no 510, de 07 de abril de 2016 do Conselho Nacional de Saúde (BRASIL, 2016a), que regulamenta pesquisas que envolvem seres humanos no Brasil. O estudo não ofereceu riscos mínimos aos participantes. Este estudo está vinculado ao projeto de pesquisa intitulado "Busca de Sintomáticos Respiratórios Vulneráveis em Feira de Santana-BA", aprovado pela Resolução CONSEPE 028/2017.

\section{RESULTADOS E DISCUSSÃO}

\section{CARACTERIZAÇÃO DOS PARTICIPANTES}

Os participantes da pesquisa foram em número de 5 (cinco), sendo que a idade variou de 32 a 53 anos com média aproximada de 40 anos; o estado civil com maior frequência foi casado; a escolaridade mais frequente foi nível superior completo; o regime de trabalho foi de 30 e 40 horas prevalecendo 30 horas; o tempo de formação variou de 6 a 25 anos de atividade e o tempo de atuação no programa Consultório na Rua foi de 4 a 5 anos. Sabe-se que o programa no mês de março de 2020 completou cinco anos de criação. (QUADRO 1)

Quadro1: Caracterização dos profissionais da pesquisa sobre a atuação em saúde junto às mulheres em situação de rua. Feira de Santana, BA, 2020.

\begin{tabular}{|l|l|l|l|l|l|l|}
\hline $\begin{array}{l}\text { Entrevista } \\
\text { do }\end{array}$ & Idade & $\begin{array}{l}\text { Estado } \\
\text { civil }\end{array}$ & Escolaridade & $\begin{array}{l}\text { Carga } \\
\text { horária }\end{array}$ & $\begin{array}{l}\text { Tempo de } \\
\text { formação }\end{array}$ & $\begin{array}{l}\text { Tempo de } \\
\text { serviço no } \\
\text { Consultório } \\
\text { na Rua }\end{array}$ \\
\hline E1 & 35 anos & Solteira & $\begin{array}{l}\text { Nível } \\
\text { Técnico } \\
\text { Completo }\end{array}$ & $\begin{array}{l}40 \\
\text { horas }\end{array}$ & 13 anos & 4 anos \\
\hline E2 & 32 anos & Casada & $\begin{array}{l}\text { Nível } \\
\text { Superior } \\
\text { Completo }\end{array}$ & $\begin{array}{l}30 \\
\text { horas }\end{array}$ & 8 anos & 5 anos \\
\hline E3 & 35 anos & Casada & $\begin{array}{l}\text { Nível } \\
\text { Superior } \\
\text { Completo }\end{array}$ & $\begin{array}{l}40 \\
\text { horas }\end{array}$ & 8 anos & 4 anos \\
\hline
\end{tabular}




\begin{tabular}{|l|l|l|l|l|l|l|}
\hline E4 & 53 anos & Casado & $\begin{array}{l}\text { Nível } \\
\text { Superior } \\
\text { Completo }\end{array}$ & $\begin{array}{l}30 \\
\text { horas }\end{array}$ & 6 anos & 4 anos \\
\hline E5 & 48 anos & Solteiro & $\begin{array}{l}\text { Nível } \\
\text { Superior } \\
\text { Completo }\end{array}$ & $\begin{array}{l}30 \\
\text { horas }\end{array}$ & 25 anos & 5 anos \\
\hline
\end{tabular}

FONTE: Elaborado pela autora, 2020.

A partir da análise das entrevistas, foram obtidas três categorias temáticas: Atividades desenvolvidas pela equipe do Consultório na Rua; Dificuldades no desenvolvimento do serviço em saúde para a mulher em situação de rua: adesão e reabordagem; Facilidades no desenvolvimento do serviço em saúde para a mulher em situação de rua: vínculo e acolhimento. Estas serão analisadas a seguir.

\section{ATIVIDADES DESENVOLVIDAS PELA EQUIPE DO CONSULTÓRIO NA RUA}

Pode-se observar que as ações de saúde na prática da equipe são ofertadas de acordo com o Protocolo da Atenção Básica (AB), sobre a saúde da mulher, que contempla o pré-natal, planejamento reprodutivo e prevenção de Infecções Sexualmente Transmissíveis, além das palestras, utilizando a educação em saúde como ferramenta de ensino (BRASIL, 2016b). Os profissionais relataram que as ações prestadas são palestras, utilizando a educação em saúde como ferramenta de ensino sobre planejamento familiar, prevenção de IST's; realizam a distribuição de preventivos e testes rápidos.

A equipe no Consultório na rua, por não ter uma unidade fixa para o atendimento às mulheres, isso se torna ainda mais desafiador, uma vez que é a equipe que vai ao encontro delas para prestar o atendimento, sendo necessário o encaminhamento diante de alguma demanda que não conseguem resolver. Entretanto, o encaminhamento não é garantia de mulher em situação de rua frequentar a unidade de saúde, seja por sentir-se rejeitada pela equipe de saúde ou pela clientela da unidade de saúde, além de não priorizar o cuidado consigo.

Um estudo realizado com a população de rua na cidade de Calgary no Canadá revelou barreiras que impedem o acesso aos serviços de saúde por essa população. Dentre elas, os sentimentos de vergonha e baixa autoestima foram predominantes na pessoa ao revelar para a equipe de saúde que é um morador de rua, por medo do preconceito e rejeição (CAMPBELL et al., 2015). Esse achado reitera o que foi 
supracitado, diante dos entraves que a mulher pode enfrentar para se direcionar ao serviço de saúde.

\section{DIFICULDADES NO DESENVOLVIMENTO DO SERVIÇO EM SAÚDE PARA A MULHER EM SITUAÇÃO DE RUA: ADESÃO E REABORDAGEM}

Observa-se a dificuldade de adesão ao tratamento, o que compromete a atuação de profissionais e o controle de doenças, estando diretamente relacionada às condições de vida dessas pessoas. Um fator preocupante é que esse grupo social normalmente se reporta ao serviço de saúde em situações emergenciais, não reconhece o seu corpo adoecido, até que comprometa suas atividades diárias. Com isso, é necessário despertar na mulher a importância do autocuidado e também orientar os profissionais de saúde quanto ao olhar humanizado para essa população (BRASIL, 2012a).

A dificuldade de encontrar a paciente para a reabordagem foi relatada pelos profissionais, visto que a população em situação de rua não se estabelece num local fixo, por medo da abordagem da polícia, ou por conflitos entre as PSR, dentre outros. De acordo com o Manual sobre o cuidado à saúde junto a população em situação de rua, do Ministério da Saúde, manter uma rotina de tratamento ou visitas das pessoas que vivem na rua é um desafio, devido a questão de sobrevivência na rua dia após dia. (BRASIL, 2012c).

Diante disso, é preciso ampliar o olhar para essas questões e tentar articular com a equipe de profissionais, pensando no que pode ser feito para adquirir a adesão por parte da mulher em situação de rua, criando estratégias de encontro para avaliações subsequentes das condições de saúde.

\section{FACILIDADES NO DESENVOLVIMENTO DO SERVIÇO EM SAÚDE PARA A MULHER EM SITUAÇÃO DE RUA: VÍNCULO E ACOLHIMENTO}

A atuação do profissional da eCR deve-se ter como eixo fundamental a criação de vínculo, como atividade essencial no cuidar. Através do vínculo, deve-se criar espaços onde essa mulher se torne sujeito de seu próprio cuidado, e não mero objeto de intervenção. Essa prática promove um envolvimento efetivo entre profissionais e usuários, na perspectiva de resolução de problemas, que seja eficaz e preciso (SILVA, CRUZ, VARGAS, 2015). Diante desse achado, nos resultados deste estudo observa-se que o vínculo é presente na comunicação profissional-usuário, uma vez que é mais 
importante dar resolubilidade as demandas do usuário, do que ficar preocupado com a produtividade diária.

Pelo que traz Engstrom e Teixeira (2016), o acolhimento perpassa pelo o posicionamento do profissional frente ao usuário, de forma a usar da escuta qualificada e olhar sensível, de humanização. O vínculo e acolhimento entre equipe e mulher foram percebidos durante a observação passiva no campo, na qual a mulher em situação de rua veio ao encontro da equipe e com afeto, abraçou-os e no olhar da mesma era perceptível a afeição pela equipe.

Assim, a escuta deve ser a principal ferramenta do trabalho, pois é um meio de compreensão das trajetórias e das vivências do viver na rua, não podendo desprezar o contexto social, as situações que levaram a mulher àquela realidade, e refletindo que é a mulher que conhece suas necessidades e seus desejos.

\section{CONCLUSÕES}

Esta pesquisa permitiu compreender a atuação do profissional da equipe do Consultório na Rua frente à mulher em situação de rua na cidade de Feira de Santana, como se configuram as ações dos profissionais, bem como as facilidades e dificuldades no desenvolvimento do serviço em saúde para as mulheres em situação de rua. Observase que o trabalho realizado prioriza o cumprimento de protocolos e o encaminhamento sem garantia da resolubilidade na assistência. As dificuldades são: adesão ao tratamento e encontro da paciente para a reabordagem e as facilidades: o vínculo e acolhimento.

\section{REFERÊNCIAS}

BRASIL. Ministério da Saúde. Resolução 466/12 de Conselho Nacional de Saúde. Diretrizes e Normas Regulamentadoras de pesquisas envolvendo seres humanos. Brasília: Ministério da Saúde, 12p, 2012b. Disponível em: http://bvsms.saude.gov.br/bvs/saudelegis/cns/2013/res0466_12_12_2012.html. Acesso: 28 out 2018 .

BRASIL. Ministério da Saúde. Resolução 510/16 do Conselho Nacional de Saúde. Dispõe de normas aplicáveis a pesquisas em Ciências Humanas e Sociais. Brasília: Ministério da Saúde, 2016a. Disponível em: http://bvsms.saude.gov.br/bvs/saudelegis/cns/2016/res0510_07_04_2016.html. Acesso: 31 jul 2019.

BRASIL. Ministério da Saúde. Protocolos da Atenção Básica: Saúde das Mulheres / Ministério da Saúde, Instituto Sírio-Libanês de Ensino e Pesquisa - Brasília: Ministério 
da Saúde, p. 230, 2016b.: il. ISBN 978-85-334-2360-2. Disponível em:

http://bvsms.saude.gov.br/bvs/publicacoes/protocolos_atencao_basica_saude_mulheres. pdf. Acesso: 22 mar 2020.

BRASIL. Ministério da Saúde. Secretaria de Atenção à Saúde. Departamento de Atenção Básica. Manual sobre o cuidado à saúde junto a população em situação de rua. Ministério da Saúde. Secretaria de Atenção à Saúde. Departamento de Atenção Básica. - Brasília: Ministério da Saúde, 2012a. Disponível em:

189.28.128.100/dab/docs/publicacoes/geral/manual_cuidado_populalcao_rua.pdf. Acesso: $11 \mathrm{fez} 2019$.

CAMPBELL, D. J. T. et al. Primary healthcare needs and barriers to care among Calgary's homeless populations. BMC Family Practice, v. 16, n. 139, 2015. DOI 10.1186/s12875-015-0361-3. Disponível em: https://bmcfampract.biomedcentral.com/track/pdf/10.1186/s12875-015-0361-3. Acesso: 06 abr 2020.

COELHO, E. A. C.; et al. Integralidade do cuidado à saúde da mulher: limites da prática profissional. Esc Anna Nery Rev Enferm, v. 13, n. 1, p. 154-160, 2009. Disponível em: <http://www.scielo.br/scielo.php?pid=S141481452009000100021\&script=sci_abstract\&tlng=pt $>$. Acesso em: 27 mar 2019.

ENGSTROM, E. M.; TEIXEIRA, M. B. Equipe "Consultório na Rua" de Manguinhos, Rio de Janeiro, Brasil: práticas de cuidado e promoção da saúde em um território vulnerável. Ciência \& Saúde Coletiva, v. 21, n. 6, p. 1839-1848, 2016. DOI: 10.1590/1413-81232015216.0782016. Disponível em: http://www.scielo.br/pdf/csc/v21n6/1413-8123-csc-21-06-1839.pdf. Acesso: 21 mar 2020.

SILVA, C. C.; CRUZ, M. M.; VARGAS, E. P. Práticas de cuidado e população em situação de rua: o caso do Consultório na Rua. Saúde Debate. Rio de Janeiro, v. 39, n. especial, p. 246-256, 2015. DOI: 10.5935/0103-1104.2015S005270. Disponível em: http://www.scielo.br/pdf/sdeb/v39nspe/0103-1104-sdeb-39-spe-00246.pdf. Acesso: 22 $\operatorname{mar} 2020$. 